\title{
Three-Dimensional Visualization of the Smooth Endoplasmic Reticulum in Purkinje Cell Dendrites
}

\author{
Maryann E. Martone, Ying Zhang, Victoria M. Simpliciano, Bridget O. Carragher, and Mark H. Ellisman \\ San Diego Microscopy and Imaging Resource, Department of Neurosciences, University of California at San Diego, \\ San Diego, California 92093-0608
}

\begin{abstract}
The three-dimensional organization of the smooth endoplasmic reticulum (SER) in Purkinje cell dendrites in the chick cerebellum was investigated to assess the connectivity between its various components. Three-dimensional reconstructions of the SER within portions of Purkinje cell dendrites were performed from serial sections through the cerebellar molecular layer. In addition, semithick and thick sections $(0.25-1 \mu \mathrm{m})$ of chick cerebellum in which the endomembrane system had been selectively stained were examined with an intermediate high-voltage electron microscope. Three-dimensional information was extracted from thick sections using stereo pairs and tomographic reconstructions from single axis tilt series. In contrast to its discontinuous appearance in thin sections, in both the threedimensional reconstructions and selectively stained thick sections the endoplasmic reticulum formed a highly interconnected network of tubules and cisterns extending throughout the dendritic shaft and into the spines. Several distinct morphological domains of endoplasmic reticulum were noted, including the hypolemmal cisternae, the endomembranes associated with the dendritic spines, and the tubular and cisternal endoplasmic reticulum in the dendritic shaft. In older chicks (aged 2 weeks), stacks of endoplasmic reticulum were also noted within the dendritic shaft. All elements of the SER within the dendritic shaft and spine appeared to be continuous with one another. The results of this study strongly suggest that the endoplasmic reticulum forms a complicated network that may be part of a single endomembrane system within Purkinje cell dendrite.
\end{abstract}

[Key words: $I P_{3}$ receptor, ryanodine receptor, endomembrane, three-dimensional, high-voltage electron microscopy]

The neuronal endoplasmic reticulum appears to function in the uptake, storage, and release of intracellular calcium in a manner analagous to the muscle sarcoplasmic reticulum (for reviews, see Miller, 1991; Henzi and MacDermott, 1992). Pharmacological and physiological studies suggest that at least two distinct intracellular calcium systems may be present within neurons

\footnotetext{
Received Nov. 23, 1992; revised May 14, 1993; accepted May 17, 1993.

We thank Dr. Stephen Young for helpful comments on the manuscript, Thomas Deerinck for technical advice, and David Hessler and Steve Lamont for their contribution to the software used in this work. This work was supported by NIH Grants HL27470, NS14718, NS26739, RR04050; NSF Grant DIR9206879; and a Human Frontiers of Science grant to M.H.E.

Correspondence should be addressed to Mark H. Ellisman, Ph.D., at the above address.

Copyright (c) 1993 Society for Neuroscience $0270-6474 / 93 / 134636-11 \$ 05.00 / 0$
}

and other nonmuscle cells (Thayer et al., 1988; Burgoyne et al., 1989; Thevenod et al., 1989; Malgaroli et al., 1990). One system releases calcium from intracellular stores in response to the breakdown of phosphatidylinositol-4,5-bisphosphate and is mediated by the inositol-1,4,5-trisphosphate $\left(\mathrm{IP}_{3}\right)$ receptor (Berridge and Taylor, 1988). Another system, involving an $\mathbf{I P}_{3}$ insensitive store, has also been described that releases calcium in response to caffeine (Thayer et al., 1988; Burgoyne et al., 1989; Malgaroli et al., 1990) and likely is mediated by the ryanodine receptor. Both the $\mathrm{IP}_{3}$ and ryanodine receptors have been localized at the electron microscopic level to components of the internal membrane system of cerebellar Purkinje neurons using antisera specific for these two proteins (Ross et al., 1989; Ellisman et al., 1990; Satoh et al., 1990; Villa et al., 1991; Walton et al., 1991). Each protein possessed a distinct distribution within the dendrites of Purkinje cells (Walton et al., 1991). While labeling for the $\mathrm{IP}_{3}$ receptor was found throughout the dendritic shaft, extending into dendritic spines, labeling for the ryanodine receptor was largely restricted to a subset of membranes within the dendritic shaft (Fig. 1).

The association of $\mathrm{IP}_{3}$ and ryanodine receptor labeling with different sets of smooth endoplasmic reticulum (SER) membranes is consistent with studies indicating differentially releasable pools of intracellular calcium (Kanaide et al., 1987; Burgoyne et al., 1989). Stimulation of these two receptors results in spatially distinct patterns of intracellular calcium release in adrenal chromaffin cells (Burgoyne et al., 1989) and dorsal root ganglion neurons (Thayer et al., 1988). A physical separation is also suggested by the finding in some cell types that depletion of calcium from hormone-sensitive stores, likely mediated via the $\mathrm{IP}_{3}$ receptor (Bcrridgc and Taylor, 1988), does not affect subsequent release of intracellular calcium by caffeine (Kanaide et al., 1987).

The physical basis for the separation of the $\mathrm{IP}_{3}$ and ryanodine receptors within Purkinje neurons is not known. It is possible that the two receptor systems are localized to different portions of the same membrane system and that the cell possesses a mechanism by which the ryanodine receptor is excluded from the membranes of the dendritic spines. This view is consistent with a double-labeling study indicating that the ryanodine and $\mathrm{IP}_{3}$ receptors were colocalized within a subset of membranes within the Purkinje cell body (Walton et al., 1991). Alternatively, the two receptor systems may reside within physically discontinuous membrane systems, one containing $\mathrm{IP}_{3}$ receptor extending from the dendritic shaft into the dendritic spine and another containing ryanodine receptor confined to the dendritic shaft. Consistent with this latter scenario, a separate membranebound organelle similar to but distinct from the SER and spe- 

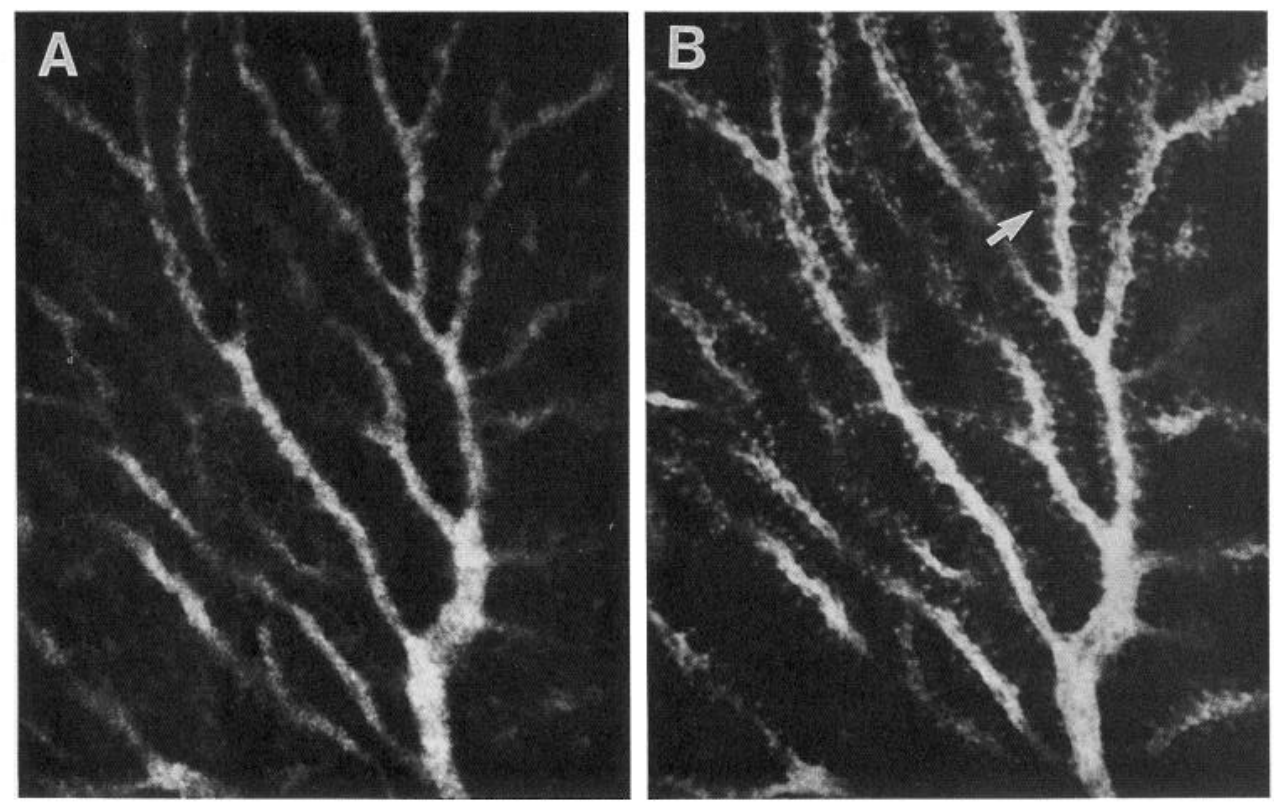

Figure 1. Purkinje cell dendrites viewed with confocal microscopy double labeled for the ryanodine receptor $(A)$ and $\mathrm{IP}_{3}$ receptor $(B) . \mathrm{IP}_{3}$ receptor labeling, unlike the ryanodine receptor, was found within dendritic spines (arrow).

cialized for the storage and release of intracellular calcium has been hypothesized to exist within a variety of cell types (Hashimoto et al., 1988; Pozzan et al., 1988; Krause et al., 1989; Milani et al., 1990; Villa et al., 1991). Like labeling for the ryanodine receptor, these organelles, which stain for the presence of calsequestrin, are restricted to the cell bodies and dendritic shafts of Purkinje cells (Villa et al., 1991).

Because of the small size and tortuous configuration of the SER, the structure of this organelle is incompletely visualized in thin sections prepared for conventional electron microscopy. Thus, although continuity between various components of the SER has been noted in electron microscopic studies of this organelle (e.g., Kaiserman-Abramof and Palay, 1969; Palay and Chan-Palay, 1974), it is difficult to determine from thin sections whether multiple networks of SER might be present. In the present study, we used several methods for examining the threedimensional ultrastructure of the SER in order to investigate whether physically distinct networks of SER exist within Purkinje cell dendrites, including (1) reconstruction of the SER within portions of Purkinje cell dendrites from serial electron micrographs, (2) examination of stereo views of thick sections in which the SER was selectively stained, and (3) tomographic reconstructions of the SER within thick sections from single axis tilt series (Frank et al., 1987; Wilson et al., 1992). The use of a variety of approaches to assess the connectivity of the SER membranes allowed for cross-validation of the conclusions derived using each method.

A brief report of this work has appeared previously (Martone et al., 1991).

\section{Materials and Methods}

\section{Immunofluorescent labeling}

The immunofluorescent images pictured in Figure 1 were taken from tissue prepared during a previous study on the distribution of $\mathrm{IP}_{3}$ and ryanodine labeling in chick cerebellum. Detailed protocols and descriptions of antibodies are provided in Walton et al. (1991).

\section{Three-dimensional reconstructions from serial sections}

Tissue preparation. Tissue in this experiment was taken from Leghorn chicks aged $24 \mathrm{hr}$ to 2 weeks. Animals were anesthetized deeply with
Nembutal and perfused through the heart with $20 \mathrm{ml}$ of oxygenated Ringer's solution containing heparin $(250 \mathrm{U} / \mathrm{ml}), 1 \%$ dextrose, and xylocaine $(0.2 \mathrm{mg} / \mathrm{ml})$ followed by $50-75 \mathrm{ml}$ of $2 \%$ paraformaldehyde, $2 \%$ glutaraldehyde in $0.15 \mathrm{~m}$ sodium cacodylate buffer. The cerebellum was removed and bisected sagittally. Parasagittal slabs approximately $1 \mathrm{~mm}$ thick were cut from the cerebellar vermis and postfixed in the same fixative as above for $2 \mathrm{hr}$. During postfixation, the tissue slabs were dissected into individual cerebellar folia. Folia were fixed in $1 \%$ osmium tetroxide for $1 \mathrm{hr}$ in $0.15 \mathrm{M}$ cacodylate buffer, rinsed with distilled water, and stained en bloc with $2 \%$ uranyl acetate for $1 \mathrm{hr}$. Tissue blocks were dehydrated through an ascending series of ethanol, followed by two changes in $100 \%$ acetone, and then embedded in Epon-Araldite.

Serial sections were cut from the molecular layer on a Ultracut E ultramicrotome (Leica) at a thickness of $80 \mathrm{~nm}$, collected on formvarcoated slot grids, counterstained with lead, and examined on a JEOL $100 \mathrm{CX}$ electron microscope. Purkinje cell dendrites were identified by their large size, extensive SER, and the presence of numerous dendritic spines (Palay and Chan-Palay, 1974). Electron micrographs at a magnification of $10,000 \times$ were recorded from sequential section series of either cross-sectioned or longitudinally sectioned dendrites.

Three-dimensional computer-assisted reconstruction. Photographic prints $(11 \times 14$ inches or $8 \times 10$ inches $)$ were made of each electron micrograph at a final magnification of $40,000-60,000 \times$. Pairs of prints were overlaid on a light box and viewed as semitransparent so as to obtain a best fit between structures continuous between planes. On this basis, three to five fiducial marks were assigned to each plane by penetrating the prints with a pin. Structures of interest, including the plasma membrane of the Purkinje cell dendrite, the SER, mitochondria, postsynaptic densities, and any presynaptic boutons impinging upon either the dendritic shaft or spines, were delineated on each print in different colors indelible ink. The contours of each structure were hand digitized into an IBM PC using a high-resolution digitizing tablet. The programs used to input, align, and display the data were developed by Dr. S. J. Young (Young et al., 1987). This program also provided area measurements for each of the profiles traced into the computer.

Surfaces were fitted to the contour data using SYNu, a suite of programs developed at the San Diego Microscopy and Imaging Resource (Hessler et al., 1992). For this data, SynuMcube, an implementation of the marching cubes algorithm, was used to fit a polygon mesh at a specified resolution to the contour data. Surface-rendered reconstructions could be viewed and manipulated using SYNUVIEW, an interactive display program.

The connectivity of the SER within the dendritic shaft in reconstructions based on serial sections was assessed using ANALYZE (Robb and Barillot, 1989), a program developed for viewing and measurement of three-dimensional volumes. ANALYZE allows the user to specify a seed point anywhere in a three-dimensional volume and to retain only those volume elements (voxels) of a specified threshold in continuity with the 

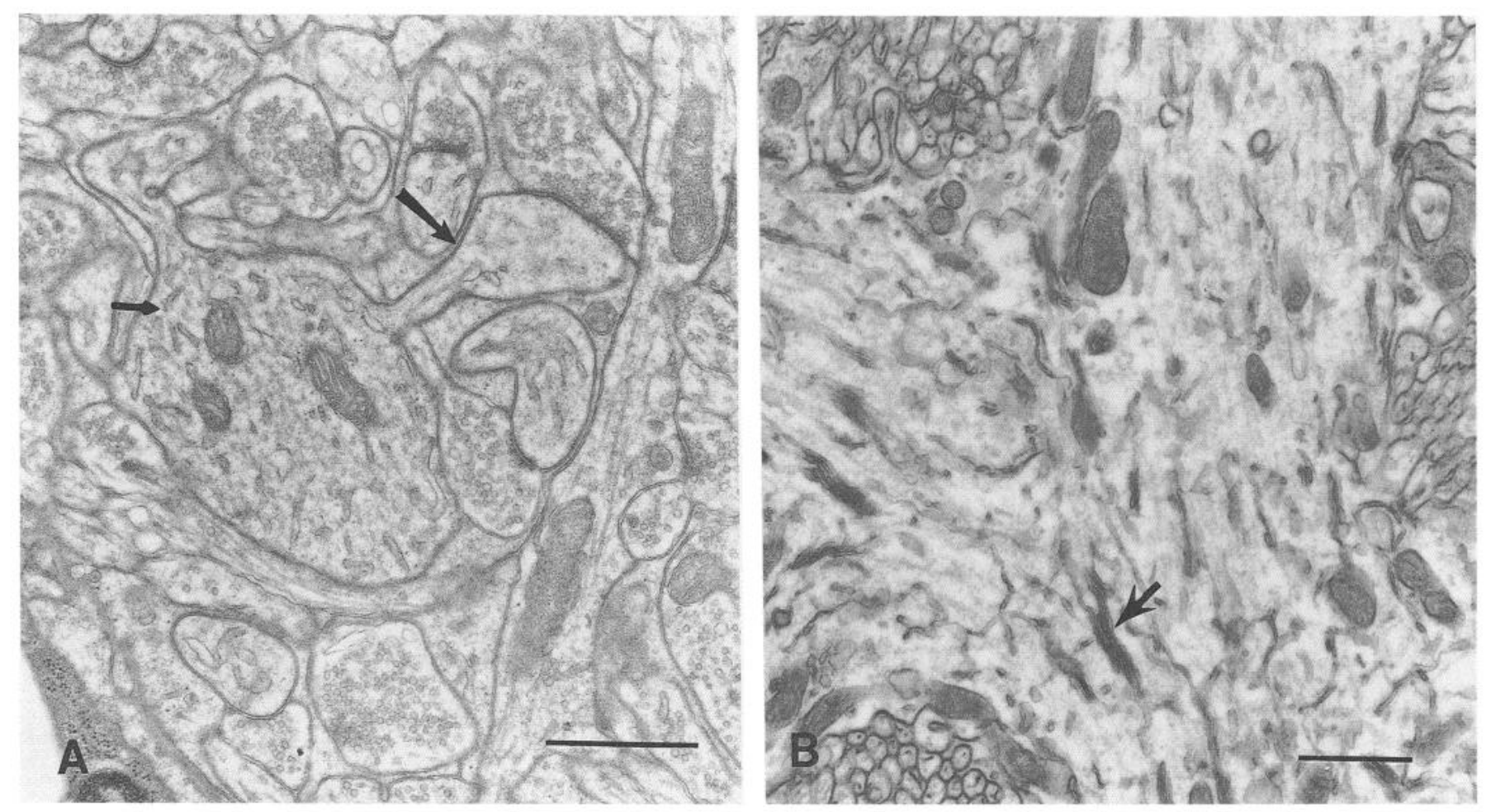

Figure 2. Photomicrographs of thin sections through Purkinje cell dendrites taken at an initial magnification of $10,000 \times$. A, Cross section of a Purkinje cell dendrite in hatchling chick. Large arrow points to a dendritic spine, and small arrow, to a profile of SER within the dendritic shaft. $B$, Longitudinal section through a branch point of a Purkinje cell dendrite in a 2-week-old chick. The presence of numerous stacks of SER (arrow) was noted in older chicks. Scale bars, $1 \mu \mathrm{m}$.

seed point. To analyze the connectivity of the SER within the threedimensional reconstructions, the profiles of SER used in the reconstructions were used to construct a volume. A seed point was selected on the SER within the interior of the dendritic shaft and those voxels that were not connected to the seed point were discarded. The resulting image was subtracted from the original image to determine the percentage of SER that was contained within a continuous network.

\section{Selective staining for intermediate high-voltage microscopy}

Since the profiles of SER seen in individual thin sections are small and thin, both alignment errors inherent in serial section reconstruction and the tiling algorithm used to fit surfaces to the contours could give false impressions of either continuity or discontinuity. Thus, in addition to serial section reconstructions, the SER was examined in thick sections of chicken cerebellum in which the SER was selectively stained.

Tissue preparation. Tissue blocks of cerebellum from 1-d- to 2-weekold Leghorn chicks were prepared as above. Selective staining of the SER was carried out using the double-impregnation technique of Thiery and Rambourg (1976) or the potassium ferrocyanide-reduced osmium technique (Forbes et al., 1977). For the double-impregnation technique, blocks of cerebellum were washed twice for $5 \mathrm{~min}$ each in $0.15 \mathrm{M}$ cacodylate buffer and then incubated in $5 \%$ aqueous uranyl acetate $\mathrm{pH}$ 4.0 ) for $60 \mathrm{~min}$ at $37^{\circ} \mathrm{C}$. Following three $5 \mathrm{~min}$ rinses in double-distilled $\mathrm{H}_{2} \mathrm{O}\left(\mathrm{ddH}_{2} \mathrm{O}\right)$, blocks were incubated for $1 \mathrm{hr}$ in a double lead-copper sulfate solution prepared according to Thiery and Rambourg (1976), rinsed twice in $\mathrm{ddH}_{2} \mathrm{O}$, and then put into $1 \%$ aqueous osmium tetroxide overnight at $4{ }^{\circ} \mathrm{C}$. Sections were rinsed in $\mathrm{ddH}_{2} \mathrm{O}$ several times, and then dehydrated and embedded in Epon-Araldite.

For the reduced osmium method, animals were perfused with the same fixative as above with $5 \mathrm{~mm}$ calcium chloride added. Following 1-2 $\mathrm{hr}$ of postfixation, the cerebellum was bisected sagittally and sectioned parasagittally at a thickness of $200 \mu \mathrm{m}$ on a Vibratome (Pelco). Sections were washed three times in $0.15 \mathrm{M}$ sodium cacodylate buffer and then incubated in $0.8 \%$ potassium ferrocyanide and $2 \%$ osmium tetroxide in $0.1 \mathrm{~m}$ cacodylate buffer for $2 \mathrm{hr}$ at room temperature. After an overnight wash in cacodylate buffer, sections were dehydrated and embedded for electron microscopy as above.
Sections ranging in thickness from 0.25 to $1 \mu \mathrm{m}$ were examined at either 200 or $400 \mathrm{keV}$ on a JEOL $4000 \mathrm{EX}$ intermediate high-voltage electron microscope (IVEM). Stereo pairs through cross-sectioned and longitudinally sectioned dendrites were taken.

Tomography from single axis tilt series. Three-dimensional volumes of the SER within thick sections were also obtained by tomographic reconstructions derived from single axis tilt series (Frank et al., 1987). One-micron-thick sections of tissue prepared with the double-impregnation technique were cut with a dry glass knife, flattened in warm $\mathrm{ddH}_{2} \mathrm{O}$, and collected on 75 mesh clamshell grids. Cross sections of Purkinje cell dendrites were identified at $400 \mathrm{keV}$ on the IVEM. The specimen was tilted through $\pm 60^{\circ}$ and micrographs of the tilted specimen were obtained every $2^{\circ}$ at a magnification of $10,000 \times$. Negatives transilluminated using a Chromopro light source were digitized at a resolution of $7 \mathrm{~nm} /$ pixel using a $1024 \times 1024 \times 14$ bit cooled CCD camera (Photometrics) with a Thomson sensor and a Nikon $105 \mathrm{~mm}$ macro lens. Tomographic reconstructions were performed on tilt series using programs in the software package sUPRIM (Stoops et al., 1991). Digitized images were flat fielded, log transformed, and aligned to a common origin using cross-correlation programs for rotational and translational alignment. A $256^{3}$ volume was produced from simple back projections of $r$-weighted tilt images. The final volume was rendered and viewed using ANALYZE.

\section{Results}

Examples of thin sections through Purkinje cell dendrites from hatchling and 2-week-old chicks are shown in Figure 2. In hatchling chicks the majority of SER appeared as small, round or elongated profiles (small arrow, Fig. $2 A$ ). In older chicks, the appearance of the SER was more complex and membrane stacks consisting of two to five lamellae of SER were noted in some dendrites (arrow in $2 B$ ). These stacks were never seen in hatchling chicks but have been reported in Purkinje neurons of adult chickens and rats (Satoh et al., 1990; Takei et al., 1992). In our 

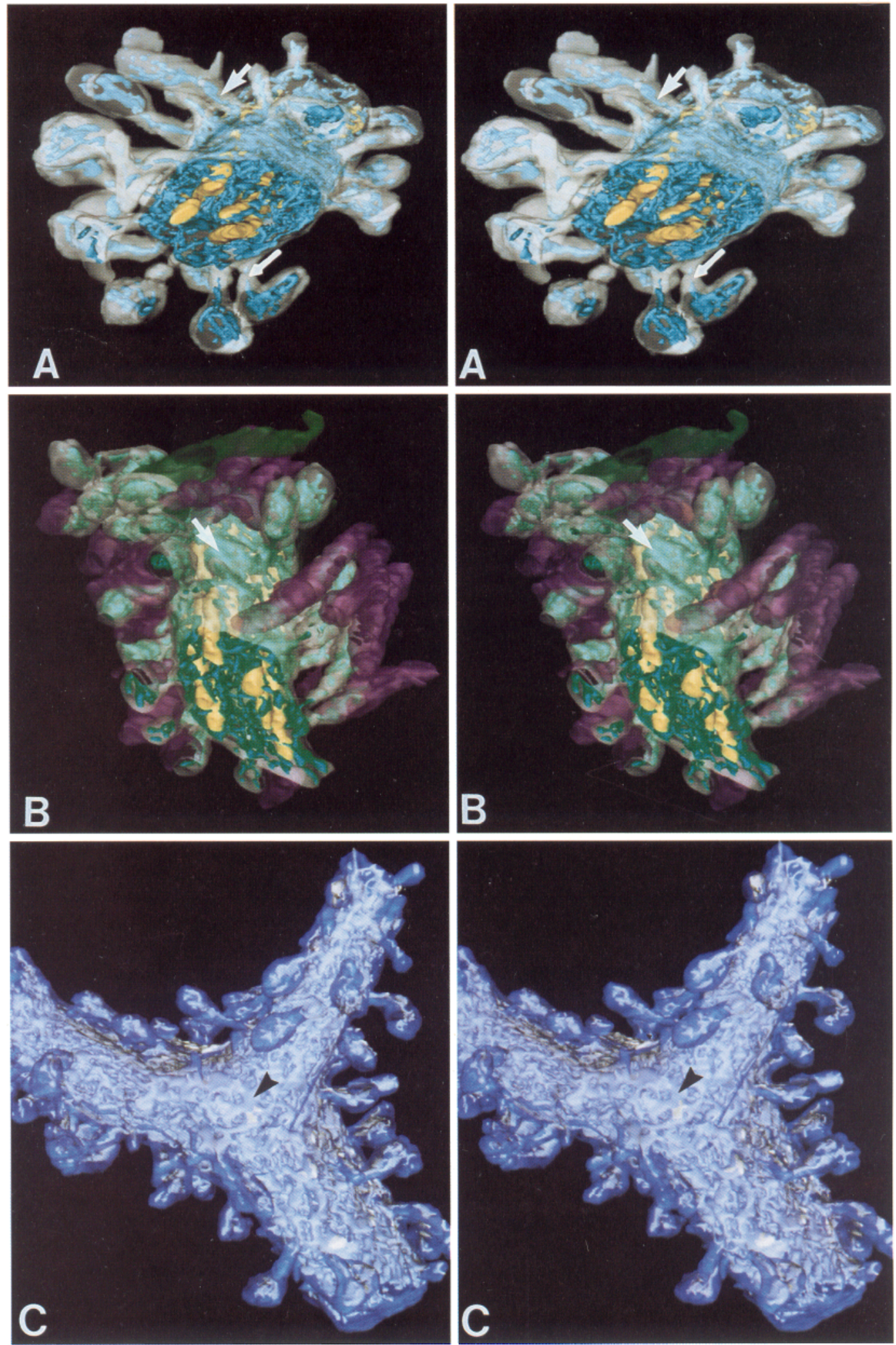

Figure 3. Stereopairs of reconstructions of the SER in portions of Purkinje cell dendrites. A, Reconstruction based on 35 serial sections (approximately $2.8 \mu \mathrm{m}$ ). The SER is shown in blue, the mitochondria in yellow, and the plasma membrane in gray. The SER within the dendritic shaft was usually continuous with that in the spine shaft (thick arrow), although occasionally small discontinuities were noted (thin arrow). B, Reconstruction based on 35 serial sections $(2.8 \mu \mathrm{m})$ showing the SER in blue-green, the mitochondria in yellow, the plasma membrane in gray, and the synaptic boutons of parallel fibers (maroon) impinging upon dendritic spines. A fiber synapsing onto the dendritic shaft is colored dark green. The locations of expanded hypolemmal cisternae (arrow) do not appear to correspond to regions of synaptic input onto the dendritic shaft. $C$, Stereopair of a portion of a branching Purkinje cell dendrite based on 56 serial sections. The SER is shown in white and the plasma membrane in dark gray. The expansion of the SER into the hypolemmal cisternal system just beneath the plasma membrane is clearly seen in this reconstruction (arrowhead). 
Figure 4. Stereopairs of Purkinje cell dendrites stained by double impregnation with copper and lead salts. $A$, Cross section of a Purkinje cell dendrite with a single dendritic spine (arrow) in a $0.25 \mu \mathrm{m}$ section photographed at $200 \mathrm{keV}$. The SER and mitochondria are filled with reaction product but the plasma membrane is barely visible (arrow). The continuity between the SER within the spine and main dendritic shaft is clearly seen. $B$, Longitudinal section of a Purkinje cell dendrite in a $1-\mu \mathrm{m}$-thick section photographed at $400 \mathrm{keV}$. The SER within numerous spines can be seen emerging from the main dendritic shaft (arrowheads). Synaptic vesicles within boutons impinging upon the spines can also be seen (arrow). Scale bars, $1 \mu \mathrm{m}$.
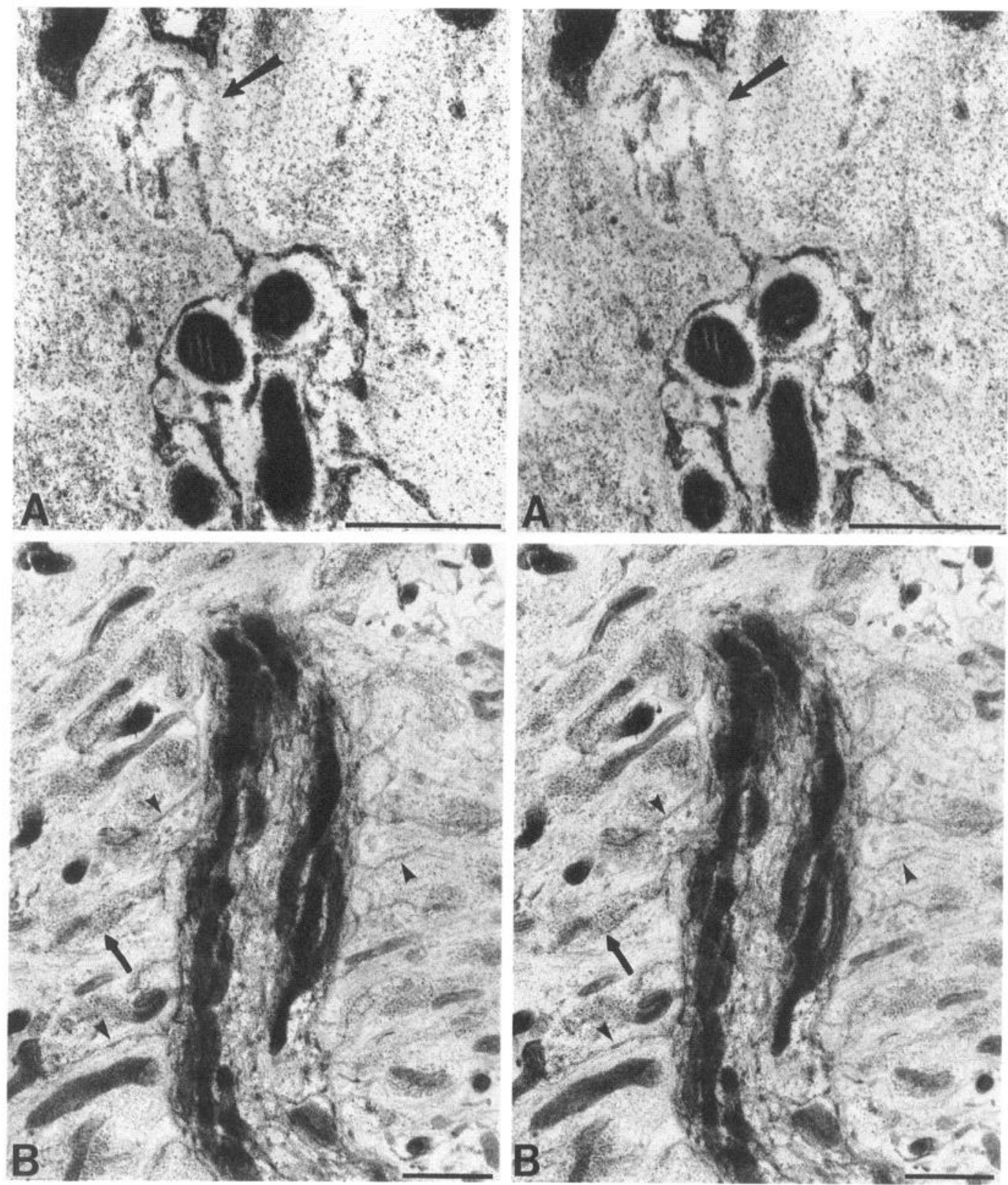

material, the stacks appeared particularly prominent in areas exhibiting sparse cytoplasmic ground substance, a sign of less than optimal fixation (Fig. $2 B$ ).

Three-dimensional reconstructions from serial sections. Stereopairs of reconstructions from serial sections of the SER in portions of Purkinje neurons are shown in Figure 3. As can be seen from such reconstructions, the SER forms a complex series of cisterns and tubules within the dendritic shaft, extending into the dendritic spines. While it appeared from these reconstructions that the SER occupied a large portion of the total dendritic volume, area measurements of the SER within thin sections indicated that it comprised only $10-20 \%$ of the total dendritic area. The form of the SER in these reconstructions appeared to be consistent with descriptions of this organelle derived from observations of thin sections (Palay and Chan-Palay, 1974; Henkart et al., 1976; Broadwell and Cataldo, 1983; Peters et al., 1991). The SER within the interior of the dendritic shaft gen- erally took the form of an anastomosing network of tubules running more or less parallel to the long axis of the dendrite. Just underneath the plasma membrane, the SER expanded into a series of interconnected flattened cisterns, the hypolemmal cisternae (Fig. $3 B, C$ ), which were in continuity with the tubules seen in the interior of the dendritic shaft (Kaiserman-Abramof and Palay, 1969; Palay and Chan-Palay, 1974). While expanded hypolemmal cisterns were usually seen at the base of spines, these cisterns were not found exclusively associated with spines, nor did their presence correlate with the location of synaptic inputs onto the dendritic shaft. Specializations of the hypolemmal cisternae-the subsurface cisterns, characterized by collapsed lumen, close apposition to the plasma membrane, and a fuzzy material interposed between plasma and cisternal membranes (Rosenbluth, 1962; Siegesmund, 1968; Henkart et al., 1976; Broadwell and Cataldo, 1983)-were not observed in the present study. These specializations are rarely observed outside 

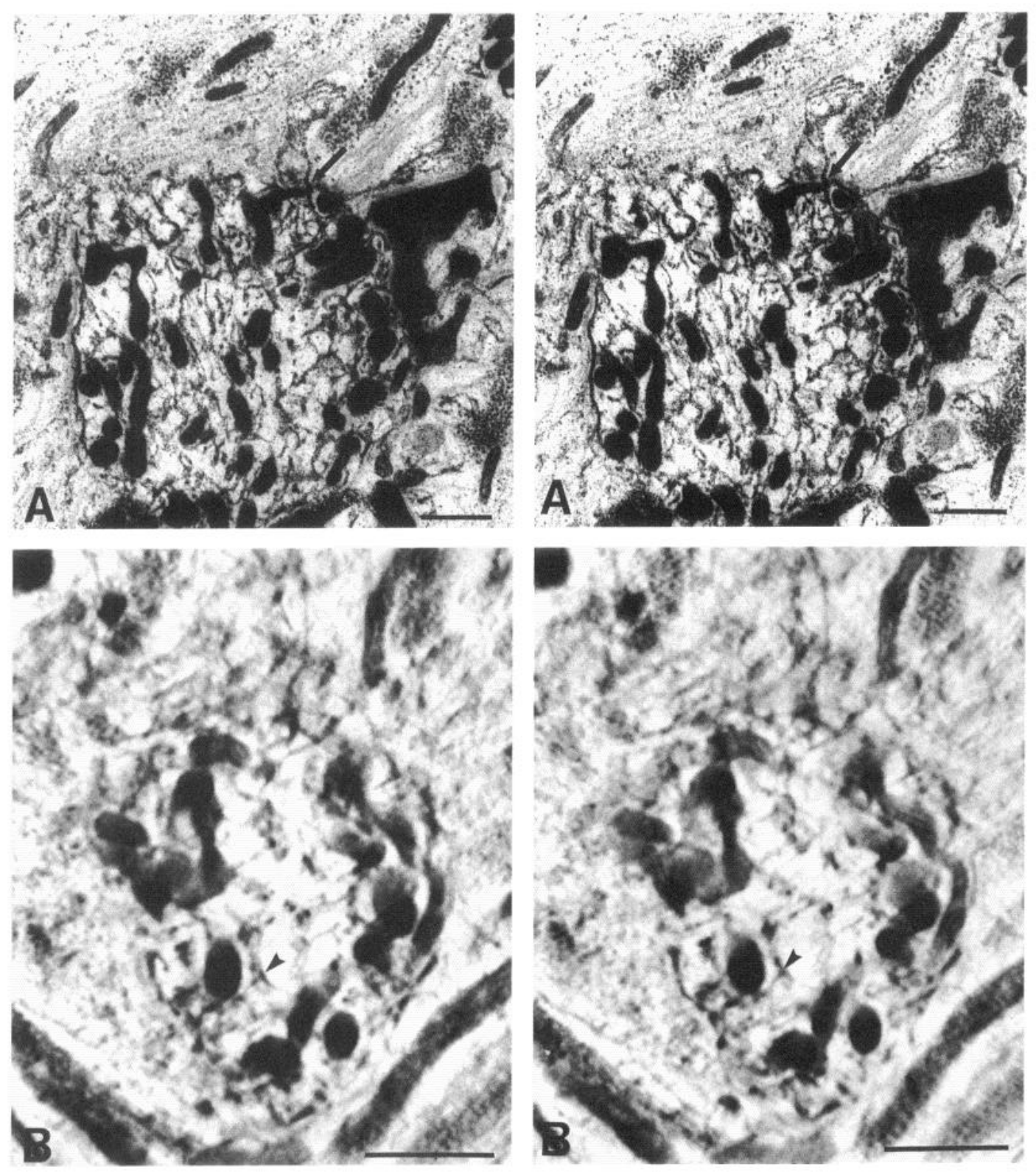

Figure 5. Stereopairs of Purkinje cell dendrites stained by double impregnation with copper and lead salts. The majority of SER profiles within the dendritic shaft are connected to each other via three-way junctions (arrowhead in B). Three-way junctions are also sometimes seen between the hypolemmal cisternae, the tubular SER within the dendritic shaft, and the SER within the spine shaft (arrow in A). A, A $0.25 \mu \mathrm{m}$ section through cross-sectioned Purkinje cell dendrite photographed at 200 keV. $B$, Tomographic volume reconstruction of SER within a $1 \mu \mathrm{m}$ section of a cross-sectioned Purkinje cell dendrite. Scale bars, $1 \mu \mathrm{m}$.

of the cell body and proximal dendrites of cerebellar Purkinje neurons (Rosenbluth, 1962; Palay and Chan-Palay, 1974).

Because the most striking difference in the distribution of the $\mathrm{IP}_{3}$ and ryanodine receptors occurred between dendritic shaft and spine, special attention was paid to the organization of the SER in the transition between shaft and spine. In many cases, the SER within the spine shaft was continuous with that of the main dendrite (arrow, Fig. $3 A$ ), as has been reported in previous three-dimensional studies in Purkinje cells (Spacek, 1985; Harris and Stevens, 1988a,b). However, small discontinuities were noted in the SER within the spine shaft in some spines (thin arrow, Fig. $3 A$ ).

The continuity of the SER within the dendritic shaft was difficult to determine by visual inspection due to the complexity of the SER network. An assessment of the continuity of the SER within the dendritic shaft using ANALYZE indicated that over $90 \%$ of the profiles in the reconstructions pictured in Figure 3, $A$ and $B$, were contained within a single network. Most of the profiles that were not continuous with the main network rep- resented the cut ends of the SER network near the beginning and end of the reconstruction and some isolated profiles within the interior of the shaft. A few of the isolated profiles could be followed for more than one plane.

Selective staining of SER. Most of the observations on the SER in thick sections were derived from material prepared with the double-impregnation technique of Thiery and Rambourg (1976). This method resulted in deposition of a coarse, granular, electron-dense reaction product in the lumen of the rough and smooth endoplasmic reticulum, Golgi apparatus, mitochondria, and synaptic vesicles (Figs. 4-6). Filling of the nucleus, and in some cases the entire cell or dendritic process, was also observed in some cells. The potassium ferrocyanide method did not lead to filling of the SER lumen but rather resulted in an increase in contrast of all membranes. This method apparently does not lead to a filling of the endoplasmic reticulum lumen in all cell types (Tsukita and Ishikawa, 1976; Forbes et al., 1977).

Examples of selectively stained semithick and thick sections of Purkinje cell dendrites are shown in Figures 4-6. A tomo- 
Figure 6. Stereopairs through branch points of Purkinje cell dendrites. A, A $0.5 \mu \mathrm{m}$ section stained with double-impregnation technique. $B$, A $0.5 \mu \mathrm{m}$ section stained with potassium ferrocyanide method. Large arrowhead points to a vesicular profile connected to the main SER network by a thin stalk. Both tubular SER with electron-dense membranes (small arrowhead) and cisternal SER exhibiting more uniform electron density are observed. Cisternal SER appeared to be particularly prominent at branch points (arrowhead in A). Scale bars, $1 \mu \mathrm{m}$.
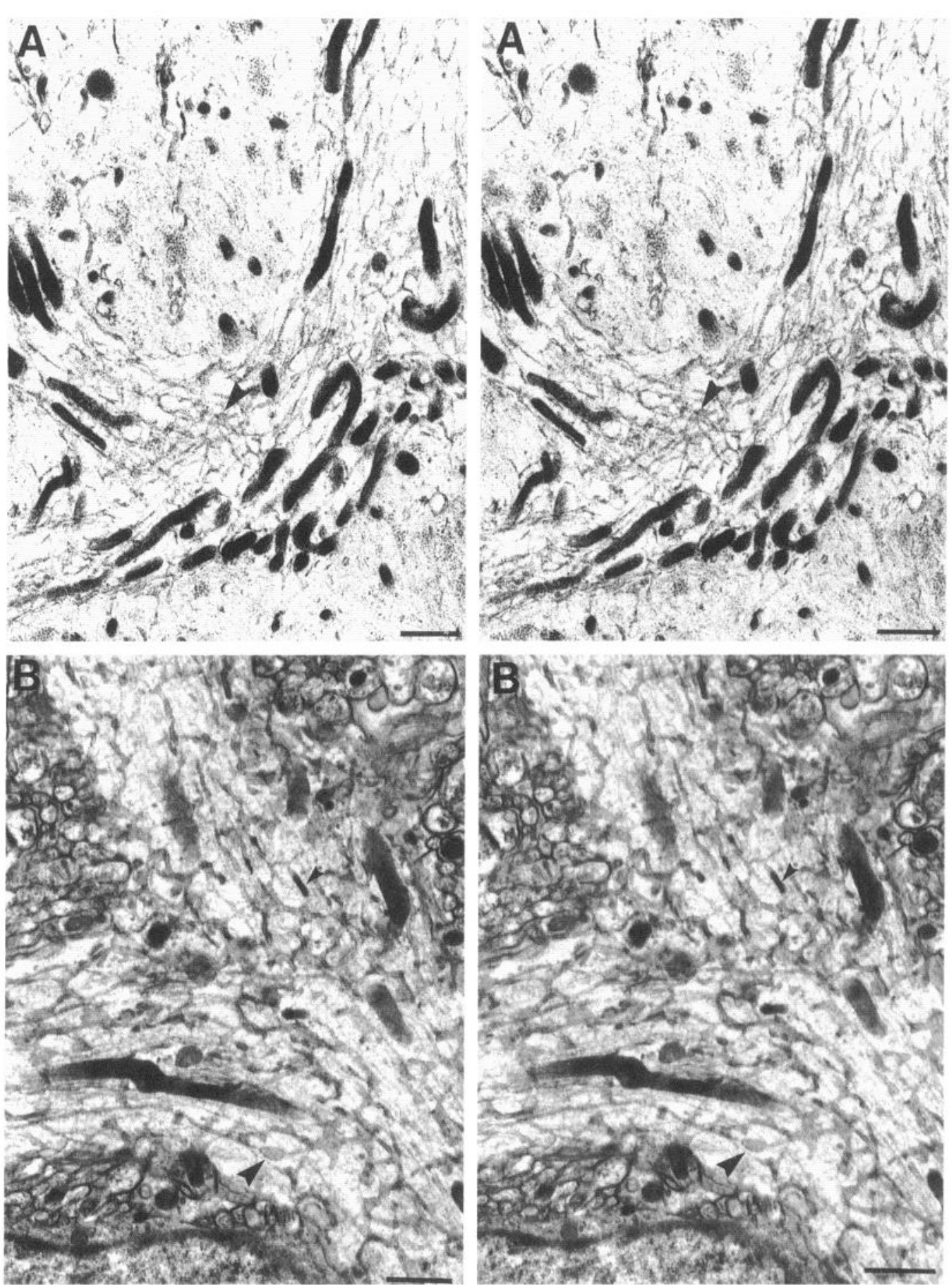

graphic reconstruction of the SER within a cross-sectioned Purkinje cell dendrite is shown in Figure $5 B$. Consistent with observations based on three-dimensional reconstructions, the majority of SER within the dendritic shaft in preparations stained by either method was contained within a single network of anastomosing tubules and cisterns. Several additional features of the SER not apparent in three-dimensional reconstructions were noted within thick sections examined using IVEM. In material stained with the potassium ferrocyanide method, two types of staining were seen. The tubular SER was often characterized by densely stained membranes (small arrowhead, Fig. $6 B$ ), while the cisternal SER was more uniformly electron dense with a more delicate, vellate appearance (Fig. $6 B$ ). Vesicular profiles of varying shapes were also noted throughout the dendritic shaft, many of which were connected to the SER network by thin stalks (large arrowhead, Fig. $6 B$ ). In tissue stained with either method, the cisternal SER often appeared concentrated at dendritic branch points (Fig. 6). The longitudinal SER within the interior of the dendritic shaft formed frequent trifurcations (Fig. $5 B$ ), an observation also made by Terasaki (1990) in living cells, and was connected to the hypolemmal cisternal system by radial extensions (Fig. $4 B$ ). The SER in the spine shaft and the hy- 
polemmal cisternae were usually continuous (Fig. 5), suggesting that the small discontinuities seen in some reconstructions in this and other studies (Spacek, 1985) may have been a result of sectioning or alignment artifact. In addition, three-way junctions were often seen between the SER in the spine shaft, the hypolemmal cisternae, and a tubal profile of SER extending from the interior of the dendritic shaft (arrow, Fig. 5A). However, the SER within the spine shaft was rarely observed to arise solely from tubal SER within the dendritic shaft but usually arose as an extension of the hypolemmal cisternae (Palay and ChanPalay, 1974).

\section{Discussion}

Continuity of the endoplasmic reticulum

Examination of the endomembrane system of Purkinje cell dendrites using three-dimensional techniques indicates that the various domains of SER are highly interconnected. Electron microscopic studies have distinguished subregions of SER based on morphological, histochemical, and immunocytochemical grounds. Identified domains include the tubular, stacked, and cisternal SER within the dendritic shaft, the hypolemmal and subsurface cisternae, and the SER within the spine shaft and head (Rosenbluth, 1962; Wood et al., 1974; Broadwell and Cataldo, 1983; Peters et al., 1991). All of these subregions, with the exception of the subsurface cisternae, were identified in the present study and observed to be part of a single network. This result is consistent with other three-dimensional studies of the SER in axons and muscle cells, which also observed a high degree of interconnectivity between membrane components (Droz et al., 1975; Sommer and Waugh, 1976; Tsukita and Ishikawa, 1976; Segretain et al., 1981; Spacek, 1985; Harris and Stevens, 1988a,b; Ogata and Yamasaki, 1990).

The question of whether the endoplasmic reticulum is a single network or is present as multiple networks has been raised by several authors (Villa et al., 1991; Walton et al., 1991; Bertolino and Llinas, 1992). Since not all regions of the endoplasmic reticulum appear to function equally in calcium storage and release (Walz, 1982; Jorgensen and Campbell, 1984; Jorgensen et al., 1985; Jorgensen and McGuffee, 1987; Villa et al., 1991; Walton et al., 1991), this issue has importance for understanding both the organization of calcium regulatory systems within neurons and the nature of the organelle responsible for intracellular calcium storage. Several authors have proposed the existence of an organelle specialized for the storage and release of calcium that is biochemically and physically distinct from the endoplasmic reticulum (Hashimoto et al., 1988; Milani et al., 1990; Rossier and Putney, 1991; Villa et al., 1991). Staining for calsequestrin, a calcium-binding protein found within the lumen of the sarcoplasmic reticulum (Jorgensen and Campbell, 1984; Jorgensen et al., 1985; Jorgensen and McGuffee, 1987), has been observed within a subset of round or irregularly shaped endomembrane compartments in a variety of cell types including Purkinje cells (Villa et al., 1991; Takei et al., 1992). These membrane compartments, termed "calciosomes," were proposed to be distinct from endoplasmic reticulum because they do not stain for the endoplasmic reticulum lumenal markers such as Bip nor are they observed to be physically continuous with the SER in electron microscopic analyses of thin sections (Hashimoto et al., 1988; Krause et al., 1989; Villa et al., 1991; Takei et al., 1992).

The existence of calciosomes as discrete entities has been questioned by several authors (e.g., Koch, 1990; Michalak et al., 1991), and in the present study isolated profiles of SER were rarely observed in thick sections examined with IVEM. Even vesicular profiles were often connected to the main network by thin stalks. While it is conceivable that the selective stains employed in this study did not reveal calciosomes, this appears unlikely since neither method was selective for the endoplasmic reticulum. The double-impregnation technique appeared to fill all membrane-bound organelles, including mitochondria, endoplasmic reticulum, and synaptic vesicles, while the ferrocyanide method contrasted all membranes, including the plasma membrane. Immunolocalization studies of calsequestrin within the muscle sarcoplasmic reticulum also suggest that these regions are connected with the rest of the endomembrane system (Volpe et al., 1992). Unfortunately, a quantitative assessment of the continuity of the SER proved difficult. This type of analysis was relatively easy to perform on the three-dimensional reconstructions because the profiles of SER used in the analysis were defined manually. However, it was clear from the thick sections stained with either selective staining method that the SER contained many thin connections between components (e.g., Fig. $6 B$ ). These connections could be easily lost in the serial section reconstruction approach if they were not caught in a favorable plane of section. That such losses did occur was suggested by the discontinuities occasionally seen in reconstructions of the SER within the spine shaft. In thick sections in which the whole of the spine shaft was contained within the section, this discontinuity was never observed (see Fig. $4 A, B$ ). Thus, although the analysis of the three-dimensional reconstructions indicated that a small portion of SER might be physically separate from the main network, this may have resulted from sectioning or reconstruction artifacts. Alternatively, it is equally possible that alignment errors or section distortion would cause profiles to appear connected when they are not. A quantitative continuity assessment was attempted on the three-dimensional tomographic volumes, but the SER could not be segmented by thresholding from the mitochondria and nonspecific precipitates that were also present.

\section{Localization of the $\mathrm{IP}_{3}$ and ryanodine receptors}

Although it is not possible to conclude with absolute certainty that only a single network of SER exists within the dendrites of Purkinje cells, the high degree of connectivity between various endomembrane components suggests that the vast majority of SER is interconnected. Thus, the different distribution of immunolabeling for the ryanodine and $\mathrm{IP}_{3}$ receptors within the Purkinje cell dendrite (Walton et al., 1991) does not appear to be due to the presence of physically separate networks of SER. The exclusion of the ryanodine receptor from the SER within dendritic spines suggests that the SER, like the plasma membrane, can regulate the distribution of membrane proteins possibly through interactions with the cytoskeleton. Interactions of the endoplasmic reticulum with cytoskeletal elements have been observed in cultured cells (Terasaki et al., 1986). Domains of endoplasmic reticulum that are associated with either actin or microtubules have been identified in the honeybee photoreceptor (Baumann, 1992), suggesting that regions of SER may be distinguished by their cytoskeletal interactions. A possible association between the $\mathrm{IP}_{3}$ receptor and actin filaments has recently been reported (Rossier et al., 1991). Future studies focusing on the interactions of the $\mathrm{IP}_{3}$ and ryanodine receptors with cytoskeletal and other associated proteins will likely yield 
important insight into spatial organization of $\mathrm{Ca}^{2+}$ buffering and release mechanisms.

While the $\mathrm{IP}_{3}$ and ryanodine receptors appear to reside in the same membrane system, it is not known whether they access the same intracellular calcium pool. Some pharmacological studies indicate that the two receptors reside over spatially separate pools (Kanaide et al., 1987; Thayer et al., 1988; Burgoyne et al., 1989) although other studies have indicated that they release calcium from the same stores (Zacchetti et al., 1991). It appears from immunocytochemical studies in Purkinje cells that the two proteins may coexist in some regions of SER (Walton et al., 1991), but that one or the other protein may predominate in other regions. In addition to its high concentration within spines, several groups have shown that labeling for the $\mathrm{IP}_{3}$ receptor is particularly concentrated within the stacks of endoplasmic reticulum (Satoh et al., 1990; Takei et al., 1992). As discussed in Takei et al. (1992), membranc stacks have becn considered to be fixation artifacts (e.g., Herndon, 1964), and in the present study these stacks did appear to be most prominent in areas displaying suboptimal fixation. However, stacks were never observed in hatchling chicks, suggesting that their presence in older chicks may reflect developmental reorganization of the SER.

Immunolocalization studies on the distribution of the ryanodine receptor in Purkinje neurons did not note its association with any particular membrane component within the dendritic shaft (Ellisman et al., 1990; Walton et al., 1991), but there are several lines of evidence suggesting that ryanodine receptors may be colocalized with calsequestrin-rich regions of the SER. First, labeling for both proteins is found only within the dendritic shaft of Purkinje cells and not within dendritic spines (Ellisman et al., 1990; Villa et al., 1991; Walton et al., 1991; Takei ct al., 1992). Sccond, subccllular fractionation studies have shown that the calsequestrin-rich component is also rich in ryanodine-binding sites (Volpe et al., 1991). Third, these two proteins are colocalized within the junctional sarcoplasmic reticulum within muscle (Jorgensen and Campbell, 1984; Jorgensen et al., 1985; Airey et al., 1990). Since membrane stacks do not stain heavily for the presence of calsequestrin (Takei et al., 1992), the SER within the dendritic shaft may contain specialized subdomains, one in which $\mathrm{IP}_{3}$ receptors are concentrated (stacks) and one in which calsequestrin/ryanodine are concentrated.

Unlike the membrane stacks that are easily identified in unlabeled tissue, the regions of SER which contain calsequestrin have not been identified solely on morphological grounds. Within muscle, both the ryanodine receptor and calsequestrin have been localized to the T-tubule-sarcoplasmic reticulum (TSR) junction (Jorgensen et al., 1985; Airey et al., 1990). The structural similarity between the TSR junction in muscle and the subsurface cisternae in neurons has been noted previously (Henkart et al., 1976). Subsurface cisternae are not found within dendrites, however, while labeling for both calsequestrin and the ryanodine receptor is found throughout the dendritic tree (Ellisman et al., 1990; Villa et al., 1991). In addition to its presence within terminal cisternae, calsequestrin has been localized in muscle within nonjunctional cisternae and the corbular sarcoplasmic reticulum (Jorgensen and Campbell, 1984; Jorgensen et al., 1985; Jorgensen and McGuffee, 1987). This latter region has been described in three-dimensional studies as a series of vesicular profiles attached to the sarcoplasmic reticulum by thin stalks and has been reported to possess "foot structures" similar to those seen at the TSR junction (Sommer and Waugh, 1976; Ogata and Yamasaki, 1990). Unlike the terminal cisternae, neither of these regions are closely apposed to the plasma membrane. In the present study, both cisternal and vesicular profiles were seen distributed throughout the dendrites of Purkinje cells. In tissue stained with the potassium ferrocyanide method, the cisternal SER could be distinguished from the tubular SER by both its shape and its moderately electrondense appearance. This latter observation is interesting given that calsequestrin-rich regions of SER identified in immunocytochemical studies have also been described as moderately electron dense in appearance (Villa et al., 1991). Whether the cisternal SER plays a role in intracellular calcium regulation remains to be determined. It was interesting to note, however, that cisternal SER appeared concentrated at dendritic branch points where increased immunolabeling for both the $\mathrm{IP}_{3}$ and ryanodine receptors has been reported (Ellisman et al., 1990; Walton et al., 1991).

\section{Conclusions}

The physiological role of intracellular calcium stores mediated by either the $\mathrm{IP}_{3}$ or ryanodine receptor is not well understood, but changes in intracellular calcium play an important role in many neuronal events (see Kennedy, 1989; Miller, 1991; Henzi and MacDermott, 1992, for reviews). Two recent studies have indicated that the neuron may possess a mechanism to restrict the diffusion of calcium within dendrites. Müller and Connor (1991) found in hippocampal slices that increases in intracellular calcium generated within dendritic spines in response to synaptic input were not paralleled by an increase in intracellular calcium within the dendritic shaft. Conversely, Guthrie et al. (1991) demonstrated that changes in calcium levels within the dendritic shaft induced by various experimental manipulations did not always result in similar changes in dendritic spines. Although the role of intracellular calcium stores in the production of neuronal calcium transients is not clear (Lev-Ram et al., 1992; Miyakawa et al., 1992), the distribution of intracellular storage, uptake, and release sites within the three-dimensional SER network may be important for shaping intracellular calcium responses.

\section{References}

Airey JA, Beck CF, Murakami K, Tanksley SJ, Deerinck TJ, Ellisman MH, Sutko JL (1990) Identification and localization of two triad junctional foot protein isoforms in mature avian fast twitch skeletal muscle. J Biol Chem 265:14187-14194.

Baumann $O$ (1992) Structural interactions of actin filaments and endoplasmic reticulum in honeybee photoreceptor cells. Cell Tissue Res 268:71-79.

Berridge MJ, Taylor CW (1988) Inositol trisphosphate and calcium signaling. Cold Spring Harbor Symp Quant Biol 53:927-933.

Bertolino M, Llinas RR (1992) The central role of voltage-activated and receptor-operated calcium channels in neuronal cells. Annu Rev Pharmacol Toxicol 32:399-421.

Broadwell RD, Cataldo AM (1983) The neuronal endoplasmic reticulum: its cytochemistry and contribution to the endomembrane system. I. Cell bodies and dendrites. J Histochem Cytochem 31:10771088.

Burgoyne RD, Cheek TR, Morgan A, O'Sullivan AJ, Moreton RB, Berridge MJ, Mata AM, Coyler J, Lee AG, East JM (1989) Distribution of two distinct $\mathrm{Ca}^{2+}$-ATPase-like proteins and their relationships to the agonist-sensitive calcium store in adrenal chromaffin cells. Nature 342:72-74.

Droz B, Rambourg $\Lambda$, Koenig HL (1975) The smooth endoplasmic reticulum: structure and role in the renewal of axonal membrane and synaptic vesicles by fast axonal transport. Brain Res 93:1-13. 
Ellisman MH, Deerinck TJ, Ouyang Y, Beck CF, Tanksley SJ, Walton PD, Airey JA, Sutko JL (1990) Identification and localization of ryanodine binding proteins in the avian central nervous system. Neuron $5: 135-146$.

Forbes MS, Plantholt BA, Sperelakis N (1977) Cytochemical staining procedures selective for sarcotubular systems of muscle: modifications and applications. J Ultrastruct Res 60:306-327.

Frank J, McEwen BF, Radermacher M, Turner JN, Rieder CI (1987) Three-dimensional tomographic reconstruction in high voltage electron microscopy. J Electron Microsc Tech 6:193-205.

Guthrie PB, Sengal M, Kater SB (1991) Independent regulation of calcium revealed by imaging dendritic spines. Nature 354:76-80.

Harris KM, Stevens JK (1988a) Dendritic spines of rat cerebellar Purkinje cells: serial electron microscopy with reference to their biophysical characteristics. J Neurosci 8:4455-4469.

Harris KM, Stevens JK (1988b) Study of dendritic spines by serial electron microscopy and three-dimensional reconstructions. In: Intrinsic determinants of neuronal form and function (Lasek RJ, Black MM, eds), pp 179-199. New York: Liss.

Hashimoto S, Bruno B, Lew DP, Pozzan T, Volpe P, Meldolesi J (1988) Immunocylochemistry of calciosomes in liver and pancreas. J Cell Biol 107:2523-2531.

Henkart M, Landis DMD, Reese TS (1976) Similarity of junctions between plasma membranes and endoplasmic reticulum in muscle and neurons. J Cell Biol 70:338-347.

Henzi V, MacDermott AB (1992) Characteristics and function of $\mathrm{Ca}^{2+}$ and inositol 1,4,5-trisphosphate-releasable stores of $\mathrm{Ca}^{2+}$ in neurons. Neuroscience 46:251-273.

Herndon RM (1964) Lamellar bodies, an unusual arrangement of the granular endoplasmic reticulum. J Cell Biol 20:338-342.

Hessler D, Young SJ, Carragher BO, Martone ME, Lamont S, Whittaker M, Milligan RA, Masliah E, Henshaw JE, Ellisman MH (1992) Programs for visualization in three-dimensional microscopy. Neuroimage 1:55-68.

Jorgensen AO, Campbell KP (1984) Evidence for the presence of calsequestrin in two structurally different regions of myocardial sarcoplasmic reticulum. J Cell Biol 98:1597-1602.

Jorgensen AO, McGuffee LJ (1987) Immunoelectron microscopic localization of sarcoplasmic reticulum proteins in cryofixed, freezedried and low temperature-embedded tissue. J Histochem Cytochem 35:723-732.

Jorgensen AO, Shen AC-Y, Campbell KP (1985) Ultrastructural localization of calsequestrin in adult rat atrial and ventricular muscle cells. J Cell Biol 101:257-268.

Kaiserman-Abramof IR, Palay SL (1969) Fine structural studies of the cerebellar cortex in a mormyrid fish. In: Neurobiology of cerebcllar evolution and development (Llinas R, ed), pp 171-205. Chicago: American Medical Association.

Kanaide H, Shogakiuchi Y, Nakamura M (1987) The norepinephrinesensitive $\mathrm{Ca}^{2+}$-storage site differs from the caffeine-sensitive site in vascular smooth muscle of the rat aorta. FEBS Lett 214:130-134.

Kennedy MB (1989) Regulation of neuronal function by calcium. Trends Neurosci 12:470-475.

Koch GLE (1990) The endoplasmic reticulum and calcium storage. Bioessays 12:527-531.

Krause K-H, Pittet D, Volpe P, Pozzan T, Meldolesi J, Lew DP (1989) Calciosome, a sarcoplasmic reticulum-like organelle involved in intracellular $\mathrm{Ca}^{2+}$-handling by non-muscle cells: studies in human neutrophils and HL-60 cells. Cell Calcium 10:351-361.

Lev-Ram V, Miyakawa H, Lasser-Ross N, Ross WN (1992) Calcium transients in cerebellar Purkinje neurons evoked by intracellular stimulation. J Neurophysiol 68:1167-1177.

Malgaroli A, Fesce R, Meldolesi J (1990) Spontaneous $\left[\mathrm{Ca}^{2+}\right]_{i}$ fluctuations in rat chromaffin cells do not require inositol 1,4,5-trisphosphate elevations but are generated by a caffeine- and ryanodinesensitive intracellular $\mathrm{Ca}^{2+}$ store. J Biol Chem 265:3005-3008.

Martone ME, Zhang Y, Simpliciano VM, Carragher BO, Ellisman MH (1991) Three-dimensional visualization of the internal membrane system of avian Purkinje cell dendrites. Soc Neurosci Abstr 17:1573.

Michalak M, Baksh S, Opas M (1991) Identification and immunolocalization of calreticulin in pancreatic cells: no evidence for "calciosomes." Exp Cell Res 197:91-99.

Milani D, Malgaroli A, Guidolin D, Fasolato C, Skaper SD, Meldolesi J, Pozzan T (1990) $\mathrm{Ca}^{2+}$ channels and intracellular $\mathrm{Ca}^{2+}$ stores in neuronal and neuroendocrine cells. Cell Calcium 11:191-199.
Miller RJ (1991) The control of neuronal $\mathrm{Ca}^{2+}$ homeostasis. Prog Neurobiol 37:255-285.

Miyakawa H, Lev-Ram V, Lasser-Ross N, Ross WN (1992) Calcium transients evoked by climbing fiber and parallel fiber synaptic inputs in guinea pig cerebellar Purkinje neurons. J Neurophysiol 68:11781189.

Müller W, Connor JA (1991) Dendritic spines as individual neuronal compartments for synaptic $\mathrm{Ca}^{2+}$ responses. Nature 354:73-76.

Ogata T, Yamasaki Y (1990) High resolution scanning electron microscopic studies on the three-dimensional structure of the transverseaxial tubular system, sarcoplasmic reticulum and intercalated disc of the rat myocardium. Anat Rec 228:277-287.

Palay SL, Chan-Palay C (1974) Cerebellar cortex: cytology and organization. New York: Springer.

Peters A, Palay SL, Webster H (1991) The fine structure of the nervous system: neurons and their supporting cells, $3 \mathrm{~d}$ ed. New York: Oxford UP.

Pozzan T, Volpe P, Zorzato F, Bravin M, Krause KH, Lew DP, Hashimoto S, Bruno B, Meldolesi J (1988) The Ins $(1,4,5) \mathbf{P}_{3}$-sensitive $\mathrm{Ca}^{2+}$ store of non-muscle cells: endoplasmic reticulum or calciosomes? J Exp Biol 139:181-193.

Robb RA, Barillot C (1989) Interactive display and analysis of 3-D medical images. IEEE Trans Med Image MI-8:217-226.

Rosenbluth J (1962) Subsurface cisterns and their relationship to the neuronal plasma membrane. J Cell Biol 13:405-421.

Ross CA, Meldolesi J, Milner TA, Satoh T, Supattapone S, Snyder SH (1989) Inositol 1,4,5-trisphosphate receptor localized to endoplasmic reticulum in cerebellar Purkinje neurons. Nature 339:468-470.

Rossier MF, Putney JW (1991) The identity of the calcium-storing, inositol 1,4,5-trisphosphate-sensitive organelle in non-muscle cells: calciosome, endoplasmic reticulum or both? Trends Neurosci 14:310314.

Rossier MF, Bird GSJ, Putney JW (1991) Subcellular distribution of the calcium-storing inositol 1,4,5-trisphosphate-sensitive organelle in rat liver. Possible linkage to the plasma membrane through actin microfilaments. Biochem J 274:643-650.

Satoh T, Ross CA, Villa A, Supattapone S, Pozzan T, Snyder SH, Meldolesi J (1990) The inositol 1,4,5-trisphosphate receptor in cerebellar Purkinje cells: quantitative immunogold labeling reveals concentration in an ER subcompartment. J Cell Biol 111:615-624.

Segretain D, Rambourg A, Clermont Y (1981) Three dimensional arrangement of mitochondria and endoplasmic reticulum in the heart muscle fiber of the rat. Anat Rec 200:139-151.

Siegesmund KA (1968) The fine structure of subsurface cisterns. Anat Rec 162:187-196.

Sommer JR, Waugh RA (1976) The ultrastructure of the mammalian cardiac muscle cell with special emphasis on the tubular membrane systems. Am J Pathol 82:192-232.

Spacek J (1985) Three-dimensional analysis of dendritic spines. II. Spine apparatus and other cytoplasmic components. Anat Embryol (Berl) 171:235-243.

Stoops JK, Shroeter JP, Bretaudiere J-P, Olsen NH, Baker TS, Strickland DK (1991) Structural studies of human alpha 2-macroglobulin: concordance between projected views obtained by negative-stain and cryomicroscopy. J Struct Biol 106:172-178.

Takei K, Stukenbrok H, Metcalf A, Mignery GA, Sudhof TC, Volpe P, De Camilli P (1992) $\mathrm{Ca}^{2+}$ stores in Purkinje neurons: endoplasmic reticulum subcompartments demonstrated by the heterogeneous distribution of the InsP $_{3}$ receptor, $\mathrm{Ca}^{2+}$-ATPase, and calsequestrin. $\mathrm{J}$ Neurosci 12:489-505.

Terasaki M (1990) Recent progress on structural interactions of the endoplasmic reticulum. Cell Motil Cytoskel 15:71-75.

Terasaki M, Chen LB, Fujiwara K (1986) Microtubules and the endoplasmic reticulum are highly interdependent structures. J Cell Biol 103:1557-1568

Thayer SA, Perney TM, Miller RJ (1988) Regulation of calcium homeostasis in sensory neurons by bradykinin. J Neurosci 8:4089-4097.

Thevenod F, Dehlinger-Kremer M, Kemmer TP, Christian A-L, Potter BVL, Schulz I (1989) Characterization of inositol 1,4,5-trisphosphate-sensitive (IsCaP) and -insensitive (IisCaP) non-mitochondrial $\mathrm{Ca}^{2+}$ pools in rat pancreatic acinar cells. J Membr Biol 109:173-186.

Thiery G, Rambourg A (1976) A new staining technique for studying thick sections in the electron microscope. J Microsc Biol Cell 26:103105

Tsukita S, Ishikawa H (1976) Three-dimensional distribution of smooth 
endoplasmic reticulum in myelinated axons. J Electron Microsc (Tokyo) 25:141-149.

Villa A, Podini P, Clegg DO, Pozzan T, Meldolesi J (1991) Intracellular $\mathrm{Ca}^{2+}$ stores in chicken Purkinje neurons: differential distribution of the low affinity-high capacity $\mathrm{Ca}^{2+}$ binding protein, calsequestrin, of $\mathrm{Ca}^{2+}$ ATPase and of the ER lumenal protein, Bip. J Cell Biol 113: 779-791.

Volpe P, Villa A, Damiani E, Sharp AH, Podini P, Snyder SH, Meldolesi J (1991) Heterogeneity of microsomal $\mathrm{Ca}^{2+}$ stores in chicken Purkinje neurons. EMBO J 10:3183-3189.

Volpe P, Villa A, Podini P, Martini A, Nori A, Panzeri MC, Meldolesi J (1992) The endoplasmic reticulum-sarcoplasmic reticulum connection: distribution of endoplasmic reticulum markers in the sarcoplasmic reticulum of skeletal muscle fibers. Proc Natl Acad Sci USA 89:6142-6146.

Walton PD, Airey JA, Sutko JL, Beck CF, Mignery GA, Sudhof TC, Deerinck TJ, Ellisman MH (1991) Ryanodine and inositol trisphosphate receptors coexist in avian cerebellar Purkinje neurons. J Cell Biol 113:1145-1157.
Walk B (1982) $\mathrm{Ca}^{21}$-sequestering smooth endoplasmic reticulum in an invertebrate photoreceptor. I. Intracellular topography as revealed by OsFeCN staining and in situ Ca accumulation. J Cell Biol 93:839848.

Wilson CJ, Mastronarde DN, McEwen B, Frank J (1992) Measurement of neuronal surface area using high-voltage electron microscope tomography. Neuroimage 1:11-22.

Wood JG, McLaughlin BJ, Barber RP (1974) The visualization of concanavalin A binding sites in Purkinje cell somata and dendrites of rat cerebellum. J Cell Biol 63:541-549.

Young SJ, Royer SM, Groves PM, Kinnamon JC (1987) Three-dimensional reconstructions from serial micrographs using the IBM PC. J Electron Microsc Tech 6:207-217.

Zacchetti D, Clementi E, Fasolato C, Lorenzon P, Zottini M, Grohovaz F, Fumagalli G, Pozzan T, Meldolesi J (1991) Intracellular $\mathrm{Ca}^{2+}$ pools in PC12 cells: a unique rapidly exchanging pool is sensitive to both inositol 1,4,5-trisphosphate and caffeine-ryanodine. J Biol Chem 266:20152-20158. 